\title{
DYNAMIC FOCUSING OF AWARENESS IN FUZZY CONTROL SYSTEMS
}

\author{
Ognjen Kuljaca ${ }^{1}$, Frank L. Lewis ${ }^{2}$, Jyotirmay Gadewadikar ${ }^{3}$ and Krunoslav \\ Horvat $^{1}$ \\ ${ }^{1}$ Brodarski Institute, Zagreb, Croatia \\ okuljaca@hrbi.hr, kruno@hrbi.hr \\ ${ }^{2}$ Automation and Robotics Research Institute, The University of Texas at Arlington, \\ Arlington, TX, USA \\ lewis @uta.edu \\ ${ }^{3}$ Systems Research Institute, Alcorn State University, Alcorn State, MS, USA \\ jyodalcorn.edu
}

\begin{abstract}
Adaptive fuzzy logic control systems with Gaussian membership functions are described. A systematic simulation study of 'dynamic focusing of awareness' in fuzzy logic control systems is provided. This study shows how the final steady-state values of the membership functions change in response to varying initial membership functions, changing desired trajectory, and varying system nonlinearities. It is shown that the fuzzy logic control system is focusing on a different region of the state-space depending on these varying factors. Conclusions on higher-level behaviour of the fuzzy logic control system are drawn. A stability proof is given.
\end{abstract}

\section{KEYWORDS}

Fuzzy Logic, Nonlinear Control, Adaptive Systems

\section{INTRODUCTION}

Adaptive fuzzy logic (FL) systems are becoming more and more popular in control systems due to the ability to select initial membership functions (MFs) based on experience and intuition, and the ability to tune the MFs to learn about the unknown dynamics of the system. Due to their approximation property, FL systems can be tuned to estimate the unknown functions in dynamical systems and to reject disturbances. By now, proofs of the stability and performance of FL systems have been provided by a variety of researchers ([1], [2], [3], [4], [5], [6], [7], [8], [9], [10], [11] and others). However, the cognitive behaviour of FL controllers has yet to be investigated. Specifically, it is not known how the MFs adapt in response to changing initial MF selections, different desired trajectories, and changing system dynamics.

In this paper, we provide a systematic simulation study of "dynamic focusing of awareness" and cognitive features in FL control systems. It appears that some cognitive functions of human awareness are reflected in the behaviour of FL control systems. In Meriam-Webster's Collegiate dictionary "cognition" is defined as "the act or process of knowing including both awareness and judgment". In the Oxford Advanced Learners dictionary "cognitive" is defined as an adjective describing the noun connected with mental processes of understanding. We define here cognitive function of the FL system as the ability of the FL system to acquire knowledge of the controlled plant in it's entirety, or , in another words, to establish the base functions needed for system identification over the whole state space involved in the system operation, including the history and the present states (we connect this with the "awareness" of the system), and the 
ability of the FL system to focus on the current state trajectories (we connect this with making proper judgment of which part of the space of awareness is important at the moment).

Also, a very interesting feature considering the input layer of the fuzzy system, i.e. membership function centroids and spreads, is observed. Parameters of the MFs exhibit the features of "longterm memory", retaining the memory of the history of the state trajectories. On the other hand, the output layer of the fuzzy system, i.e. the output representative values of the FL control system, exhibit the features of "short-term memory", reacting to higher frequency components of the system excitation signal. A description of cognitive functions of fuzzy systems and longterm and short-term memory is given in [12].

In this paper the structure of the FL controller is provided, and MF tuning algorithms are given that provide rigorous stability and performance properties. A mathematical proof is proffered. Then, we study through computer simulations how the final steady-state values of the MFs change in response to varying initial MFs, changing desired trajectory, and varying system nonlinearities.

\section{DyNAMiC SYSTEM PRELIMINARIES}

Let $\mathrm{R}$ denote the real numbers, $\mathrm{R}^{\mathrm{n}}$ denote the real $\mathrm{n}$-vectors, $\mathrm{R}^{\mathrm{m} \times \mathrm{n}}$ the real $\mathrm{m} \times \mathrm{n}$ matrices. Let $S$ be a compact simply connected subset of $R^{n}$. With maps $f: S \rightarrow R^{m}$, define $C^{m}(S)$ as the space of points at which $\mathrm{f}$ is continuous. We denote by $\|\cdot\|$ a suitable vector norm. Given a matrix $A=\left\lfloor a_{i j}\right\rfloor, A \in R^{n \times m}$ the Frobenius norm is defined by

$$
\|\mathrm{A}\|_{\mathrm{F}}^{2}=\operatorname{tr}\left(\mathrm{A}^{\mathrm{T}} \mathrm{A}\right)=\sum_{\mathrm{i}, \mathrm{j}} \mathrm{a}_{\mathrm{ij}}^{2},
$$

with $\operatorname{tr}()$ the trace operation. The associated inner product is $\langle\mathrm{A}, \mathrm{B}\rangle_{\mathrm{F}}=\operatorname{tr}\left(\mathrm{A}^{\mathrm{T}} \mathrm{B}\right)$. The Frobenius norm $\|\mathrm{A}\|_{\mathrm{F}}^{2}$ is denoted by $\|\cdot\|$ throughout this paper, unless otherwise specified.

The trace of $A$ satisfies $\operatorname{tr}(\mathrm{A})=\operatorname{tr}\left(\mathrm{A}^{\mathrm{T}}\right)$ for a matrix $\mathrm{A}=\left\lfloor\mathrm{a}_{\mathrm{ij}}\right\rfloor$, and $n x n$ square matrix. For any $m x n$ matrix $\mathrm{B}$ and $n x m$ matrix $\mathrm{C}$, we have $\operatorname{tr}(\mathrm{BC})=\operatorname{tr}(\mathrm{CB})$.

Let the process have dynamics of the general nonlinear form

$$
\begin{aligned}
& \dot{\mathrm{x}}_{1}=\mathrm{x}_{2} \\
& \vdots \\
& \dot{\mathrm{x}}_{\mathrm{n}-1}=\mathrm{x}_{\mathrm{n}} \\
& \dot{\mathrm{x}}_{\mathrm{n}}=\mathrm{f}(\mathrm{x})+\mathrm{u}(\mathrm{t})+\mathrm{d}(\mathrm{t}) \\
& \mathrm{y}=\mathrm{x}_{1},
\end{aligned}
$$

with the state $x=\left[\begin{array}{lll}x_{1} & x_{2} & \ldots \\ x_{n}\end{array}\right]^{T}, \mathrm{u}(\mathrm{t})$ the control input to the plant, and $\mathrm{y}(\mathrm{t})$ the output of interest. Signal $\mathrm{d}(\mathrm{t})$ denotes the unknown disturbance, which we assume has a known upper bound $b_{d}$. The system nonlinearities are given by the smooth function $f(x): R^{n} \rightarrow R^{m}$. It is assumed that external disturbances $d(t)$ and the nonlinearity $f(x)$ in the system are unknown to the controller. Given a desired trajectory and its derivative values

$$
\mathrm{x}_{\mathrm{d}}(\mathrm{t})=\left[\begin{array}{llll}
\mathrm{x}_{\mathrm{d}} & \dot{\mathrm{x}}_{\mathrm{d}} & \cdots & \mathrm{x}_{\mathrm{d}}^{(\mathrm{n})}
\end{array}\right]^{\mathrm{T}},
$$


define the tracking error as

$$
e(t)=x_{d}(t)-x(t)
$$

A so-called filtered tracking error $r(t) \in R^{m}$ is defined as:

$$
\mathrm{r}(\mathrm{t})=\lambda_{\mathrm{n}-1} \mathrm{e}^{(\mathrm{n}-1)}(\mathrm{t})+\lambda_{\mathrm{n}-2} \mathrm{e}^{(\mathrm{n}-2)}(\mathrm{t})+\cdots+\lambda_{1} \mathrm{e}^{(1)}(\mathrm{t})+\mathrm{e}(\mathrm{t})
$$

or in matrix form

$$
r(t)=\left[\begin{array}{ll}
\Lambda^{T} & 1
\end{array}\right] \cdot e(t)
$$

where $\mathrm{e}^{(\mathrm{n}-1)}(\mathrm{t}), \ldots, \mathrm{e}^{(1)}(\mathrm{t})$ are the derivative values of the error $\mathrm{e}(\mathrm{t})$, $\overline{\mathrm{e}}(\mathrm{t})=\left[\begin{array}{lllll}\mathrm{e}^{(\mathrm{n}-1)}(\mathrm{t}) & \mathrm{e}^{(\mathrm{n}-2)}(\mathrm{t}) & \cdots & \mathrm{e}^{(1)}(\mathrm{t}) & \mathrm{e}(\mathrm{t})\end{array}\right]^{\mathrm{T}}, \quad$ and $\quad \Lambda=\left[\begin{array}{llll}\lambda_{\mathrm{n}-1} & \lambda_{\mathrm{n}-2} & \cdots & \lambda_{1}\end{array}\right]^{\mathrm{T}} \quad$ is $\quad$ an appropriate chosen vector of constant values so that $\left|s^{n-1}+\lambda_{n-2} s^{n-2}+\cdots+\lambda_{1}\right|$ is stable (i.e., Hurwitz). This means that $\mathrm{e}(\mathrm{t}) \rightarrow 0$ exponentially as $\mathrm{r}(\mathrm{t}) \rightarrow 0$. Thus, filtered error $\mathrm{r}(\mathrm{t})$ can be viewed as the real-valued instantaneous utility function of the plant performance. When $\mathrm{r}(\mathrm{t})$ is small, the system performance is good.

Using equations ( 2 ), ( 3 ) and ( 4 ) the dynamics of the performance measure signal ( 5 ) can be written as

$$
\dot{r}=g\left(x, x_{d}\right)-u(t)-d(t)
$$

where $\mathrm{g}\left(\mathrm{x}, \mathrm{x}_{\mathrm{d}}\right)$ is a complex unknown nonlinear function of the state and desired trajectory vectors $x(t)$ and $x_{d}(t)$, respectively. Note that this function includes the original system unknown nonlinear function $\mathrm{f}(\mathrm{x})$.

Uniform ultimate boundedness defined as in ([16]). was used in the stability proof.

\section{BACKGROUND ON FUZZY SYSTEMS}

To fully take advantage of the learning abilities of FL systems, in this section we describe a nonlinearly-parametrized control function. In this FL control function we tune the output representative values, but also the MF centroids and spreads. The fuzzy logic system with center average fuzzifier, product inference rule and singleton defuzzifier consist of all functions of the form ([13])

$$
\mathrm{y}_{\mathrm{j}}(\mathrm{z})=\frac{\sum_{\mathrm{l}=1}^{\mathrm{M}} \mathrm{w}_{\mathrm{j}}^{1} \prod_{\mathrm{i}=1}^{\mathrm{n}} \phi_{\mathrm{A}_{\mathrm{i}}^{\mathrm{l}}}\left(\mathrm{z}_{\mathrm{i}}, \mathrm{a}_{\mathrm{i}}^{1}, \mathrm{~b}_{\mathrm{i}}^{\mathrm{l}}\right)}{\sum_{\mathrm{l}=1}^{\mathrm{M}} \prod_{\mathrm{i}=1}^{\mathrm{n}} \phi_{\mathrm{A}_{\mathrm{i}}^{\mathrm{l}}}\left(\mathrm{z}_{\mathrm{i}}, \mathrm{a}_{\mathrm{i}}^{1}, \mathrm{~b}_{\mathrm{i}}^{\mathrm{l}}\right)}, \mathrm{j}=1,2, \ldots, \mathrm{m},
$$

with $y_{j}: U \subset R^{n} \rightarrow R, \quad \mathrm{z}=\left[\mathrm{z}_{1}, \ldots, \mathrm{z}_{\mathrm{n}}\right]^{\mathrm{T}} \in \mathrm{U}_{1} \times \cdots \times \mathrm{U}_{\mathrm{n}}$. Let $\phi_{\mathrm{A}_{\mathrm{i}}}\left(\mathrm{z}_{\mathrm{i}}, \mathrm{a}_{\mathrm{i}}^{1}, \mathrm{~b}_{\mathrm{i}}^{1}\right)$ be Gaussian membership functions defined by

$$
\phi_{A_{i}^{1}}\left(z_{i}, a_{i}^{1}, b_{i}^{1}\right)=e^{\left(-a_{i}^{\left.a^{2}\left(z_{i}-b_{i}^{1}\right)^{2}\right)}\right.} .
$$


Note that $b_{i}^{1}$ are the MF centroids and $a_{i}^{1}$ determines the MF spread or width. The control representative values are $w_{j}^{1}$. One can note that Gaussian definition in ( 9 ) is slightly different than the usual definition of Gaussian membership functions

$$
\phi_{A_{i}^{1}}\left(z_{i}, a_{i}^{1}, b_{i}^{1}\right)=e^{\left(-\frac{\left(z_{i}-b_{i}^{1}\right)^{2}}{a_{i}^{12}}\right)} .
$$

The difference is that in our definition (also in [3]) parameter "a" is positioned in the numerator of the exponent instead of its denominator. The behavior of the Gaussian function will stay the same and the tuning laws will have the same structure but with different jacobians. By placing parameter "a" in numerator a potential problem of division by 0 is avoided. That is an important feature for practical implementation.

The adjustable parameters are $\mathrm{w}_{\mathrm{i}}^{1}, \mathrm{a}_{\mathrm{i}}^{1}, \mathrm{~b}_{\mathrm{i}}^{1}$ so that this FL system is nonlinear in adjustable parameters. Let us define fuzzy basis functions (FBF) as ([13])

$$
\phi^{1}\left(\mathrm{z}, \mathrm{a}^{1}, \mathrm{~b}^{1}\right)=\frac{\prod_{\mathrm{i}=1}^{\mathrm{n}} \phi_{\mathrm{A}_{\mathrm{i}}^{\mathrm{i}}}\left(\mathrm{z}_{\mathrm{i}}, \mathrm{a}_{\mathrm{i}}^{1}, \mathrm{~b}_{\mathrm{i}}^{1}\right)}{\sum_{\mathrm{i}=1}^{\mathrm{M}} \prod_{\mathrm{i}=1}^{\mathrm{n}} \phi_{\mathrm{A}_{\mathrm{i}}^{\mathrm{i}}}\left(\mathrm{z}_{\mathrm{i}}, \mathrm{a}_{\mathrm{i}}^{1}, \mathrm{~b}_{\mathrm{i}}^{1}\right)}, \quad \mathrm{l}=1,2, \ldots, \mathrm{M},
$$

In [2], ( 11 ) is defined as multi-dimensional basis unnormalized functions. Then, the fuzzy logic system described by ( 8 ) is equivalent to an FBF expansion

$$
\mathrm{y}_{\mathrm{j}}(\mathrm{x})=\sum_{\mathrm{l}=1}^{\mathrm{M}} \mathrm{w}_{\mathrm{j}}^{1} \phi^{1}\left(\mathrm{z}, \mathrm{a}^{1}, \mathrm{~b}^{1}\right), \quad \mathrm{j}=1,2, \ldots, \mathrm{M} .
$$

The output of the fuzzy logic system ( 12 ) can be expressed in a vector notation as

$$
\mathrm{y}=\mathrm{W}^{\mathrm{T}} \Phi(\mathrm{z}, \mathrm{a}, \mathrm{b}) .
$$

According to the fuzzy logic universal approximation theorem ([13]), FBF expansions ( 13 ) are universal approximators.

\section{FL CONTROL ARCHITECTURE}

There are two distinct parts of the proposed FL control architecture: a proportional-plusderivative (PD) outer tracking loop, and a nonlinear adaptive FL loop. Without the FL adaptive loop this scheme boils down to PD control and its performance deteriorates. The FL loop is fed by plant states and desired trajectories and in essence it is used to approximate the nonlinear function $\mathrm{g}\left(\mathrm{x}, \mathrm{x}_{\mathrm{d}}\right)$ in $(7)$. Instead of desired states $\mathrm{x}_{\mathrm{d}}$, the error vector can be used as an input to the FL system since $e=x_{d}-x$. This FL logic control architecture is shown in Figure 1 .

We now derive an adaptive FL logic controller for nonlinear systems. According to the approximation properties of fuzzy logic systems, the continuous nonlinear function $g\left(x, x_{d}\right)$ in ( 7 ) can be represented as

$$
\mathrm{g}\left(\mathrm{x}, \mathrm{x}_{\mathrm{d}}\right)=\mathrm{W}^{\mathrm{T}} \Phi(\mathrm{z}, \mathrm{a}, \mathrm{b})+\varepsilon(\mathrm{z})
$$


where $\mathrm{z}$ is the input vector to the fuzzy system and the approximation error $\varepsilon(\mathrm{z})$ is bounded on a compact set by a known constant $\varepsilon_{\mathrm{N}}$. The ideal parameters a, b and W that approximate $g(\cdot)$ are unknown. Vector $z$ may be selected as $\left[\begin{array}{ll}x^{T} & x_{d}^{T}\end{array}\right]^{T}$ or as $\left[\begin{array}{ll}x^{T} & e^{T}\end{array}\right]^{T}$.

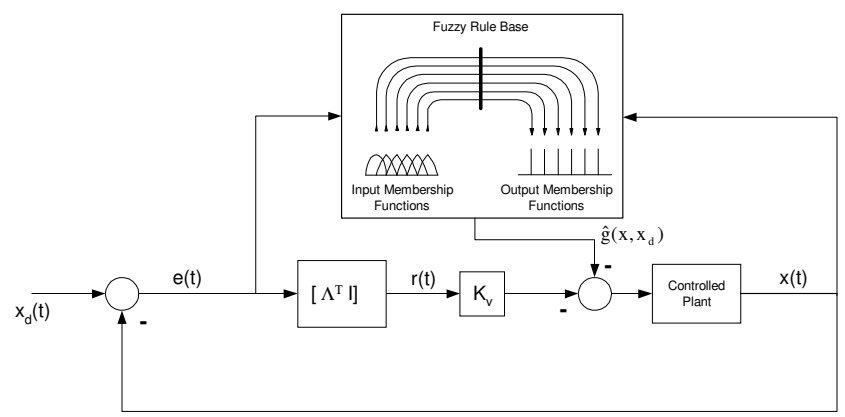

Figure 1: Fuzzy control system architecture

Let the control input $\mathrm{u}(\mathrm{t})$ be given by

$$
u(t)=K_{v} r+\hat{g}\left(x, x_{d}\right),
$$

where $\hat{\mathrm{g}}\left(\mathrm{x}, \mathrm{x}_{\mathrm{d}}\right)$ is provided by the fuzzy system and the control gain matrix is $\mathrm{K}_{\mathrm{v}}=\mathrm{K}_{\mathrm{v}}^{\mathrm{T}}>0$. Let the fuzzy functional estimate for the continuous nonlinear function $\mathrm{g}\left(\mathrm{x}, \mathrm{x}_{\mathrm{d}}\right)$ be:

$$
\hat{\mathrm{g}}\left(\mathrm{x}, \mathrm{x}_{\mathrm{d}}\right)=\hat{\mathrm{W}}^{\mathrm{T}} \Phi(\mathrm{z}, \hat{\mathrm{a}}, \hat{\mathrm{b}}) \text {, }
$$

where $\hat{a}, \hat{b}, \hat{W}$ are the actual current parameters of the FL system. Then, the filtered error dynamics ( 7 ) can be rewritten as

$$
\dot{\mathrm{r}}=-\mathrm{K}_{\mathrm{v}} \mathrm{r}+\tilde{\mathrm{g}}\left(\mathrm{x}, \mathrm{x}_{\mathrm{d}}\right)-\mathrm{d}(\mathrm{t}),
$$

where the functional estimation error is defined as $\tilde{g}\left(x, x_{d}\right)=g\left(x, x_{d}\right)-\hat{g}\left(x, x_{d}\right)$. Similar architectures are described in [3] and [14] and also in numerous other articles. Now, using ( 14 ) and ( 16 ), equation ( 17 ) can be written as

$$
\dot{\mathrm{r}}=-\mathrm{K}_{\mathrm{v}} \mathrm{r}+\mathrm{W}^{\mathrm{T}} \Phi(\mathrm{z}, \mathrm{a}, \mathrm{b})-\hat{\mathrm{W}}^{\mathrm{T}} \Phi(\mathrm{z}, \hat{\mathrm{a}}, \hat{\mathrm{b}})+\mathrm{d}(\mathrm{t})+\varepsilon .
$$

Some required mild assumptions are now stated. These assumptions will be true in most practical situations and are standard in the existing literature.

Assumption 1: The ideal FL parameters $\mathrm{W}$, $\mathrm{a}$ and $\mathrm{b}$ are bounded by known positive values so that the Frobenius norms satisfy

$$
\|\mathrm{W}\| \leq \mathrm{W}_{\mathrm{M}}, \quad\|\mathrm{a}\| \leq \mathrm{a}_{\mathrm{M}}, \quad\|\mathrm{b}\| \leq \mathrm{b}_{\mathrm{M}} .
$$

Assumption 2: The desired trajectory is bounded in the sense, for instance that

$$
\left\|\begin{array}{llll}
\mathrm{q}_{\mathrm{d}} & \dot{\mathrm{q}}_{\mathrm{d}} & \ldots & \mathrm{q}_{\mathrm{d}}
\end{array}\right\| \leq \mathrm{Q}_{\mathrm{d}} .
$$

Assumption 3: The disturbance and FL approximation error are bounded in the sense

$$
\|\mathrm{d}\| \leq \mathrm{b}_{\mathrm{d}} ; \quad\|\varepsilon\| \leq \varepsilon_{\mathrm{N}} \text {. }
$$

Now, the following theorem can be formulated. 


\section{Theorem}

Suppose that assumptions 1, 2 and 3 hold. Let the system be given by ( 2 ). Let FBF functions be defined as in ( 11 ) and fuzzy system output as in ( 13 ). Let control signal be defined by

$$
\mathrm{u}(\mathrm{t})=-\mathrm{K}_{\mathrm{v}} \mathrm{r}-\hat{\mathrm{g}}\left(\mathrm{x}, \mathrm{x}_{\mathrm{d}}\right) \text {. }
$$

Let the tuning laws for the FL system be

$$
\begin{aligned}
& \dot{\hat{\mathrm{W}}}=\mathrm{K}_{\mathrm{W}}(\hat{\Phi}-\mathrm{A} \hat{\mathrm{a}}-\mathrm{B} \hat{\mathrm{b}}) \mathrm{r}^{\mathrm{T}}-\mathrm{k}_{\mathrm{W}} \mathrm{K}_{\mathrm{W}} \hat{\mathrm{W}}\|\mathrm{r}\| \text {, } \\
& \dot{\hat{a}}=K_{a} A^{\mathrm{T}} \hat{W} r-k_{a} K_{a} \hat{a}\|r\|, \\
& \dot{\hat{b}}=K_{b} B^{T} \hat{W} r-k_{b} K_{b} \hat{b}\|r\|,
\end{aligned}
$$

where $K_{v}, K_{a}, K_{b}, K_{w}, k_{a}, k_{b}, k_{w}$ are design parameters. Then the filtered error $r$ and FL parameters $\mathrm{W}$, a and $\mathrm{b}$ will be uniformly ultimately bounded. In addition, the filtered error can be made as small as desired by increasing gain $K_{v} . \square$

The detailed proof is given in the appendix. It should be noted that no robust term is required, which is a standard feature of many of the proofs and designs for systems with similar architecture given in the literature. Also, unlike designs in [3] and [14], additional freedom of design is provided by introducing design parameters $\mathrm{k}_{\mathrm{a}}, \mathrm{k}_{\mathrm{b}}, \mathrm{k}_{\mathrm{w}}$ instead of one design parameter $\mathrm{k}$.

\section{Cognitive Behaviour of FL Control System}

In this section we propose to study through computer simulations the effects on the learned final membership functions of various effects including varying desired reference trajectories, changing system nonlinearities, and changing initial MF information stored in the FL approximator portion of the control signal. The results of this section indicate that FL controllers do indeed perform some functions of human cognitive systems, including focusing of awareness to regions of more pronounced activity, recovery from improper initial information, learning compensation for varying system dynamics, and long-term memory of past performance. We begin by noting that the FL component ( 16 ) in the control signal ( 15 ) has two components. The short-term memory resides in the values of the control representative values $\mathrm{W}$, and the long-term memory resides in the shape $(\mathrm{a}, \mathrm{b})$ of the MFs. Indeed, we observed, and shall discuss, the interesting behavior that the $\mathrm{W}$ weights tune faster and with more activity than the $(a, b)$ weights.

Detailed plots are provided in order to show the performance of the fuzzy controller. As controlled plant, a Van der Pol oscillator was used. The Van der Pol oscillator is a representative nonlinear system with rather interesting autonomous behaviour. It has dynamics given by

$$
\left[\begin{array}{c}
\dot{\mathrm{x}}_{1} \\
\dot{\mathrm{x}}_{2}
\end{array}\right]=\left[\begin{array}{c}
\mathrm{x}_{2} \\
-\mathrm{a}\left(\mathrm{x}_{1}^{2}-1\right) \mathrm{x}_{2}-\mathrm{x}_{1}+\mathrm{u}
\end{array}\right],
$$

It can be seen that the Van der Pol oscillator is in the form given in Section 2, equation ( 2 ) with $f(x)=-a\left(x_{1}^{2}-1\right) x_{2}-x_{1}$.

This system describes dynamics such as predator/prey relationships in closed ecosystems, and even long-term effects of natural selection ([15]). Phase-plane plots for the unexcited Van der Pol oscillator with initial conditions $\mathrm{x}_{0}=\left[\begin{array}{ll}1 & 1\end{array}\right]^{\mathrm{T}}$ for values of the parameter $\mathrm{a}=0.1$ and $\mathrm{a}=1$ are given in Figure 2 and Figure 3 respectively. These plots show that state trajectories change significantly with the change of parameter a. This implies that it is appropriate, and even necessary, to use adaptive control in this case. 


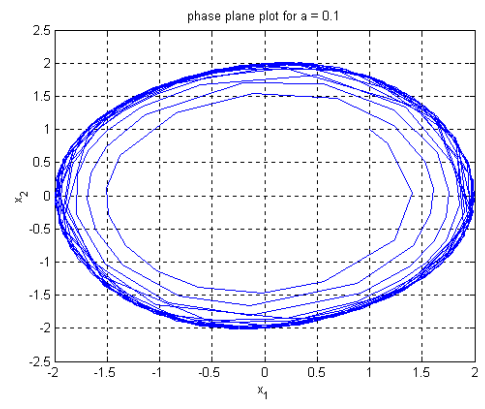

Figure 2. Phase-plane plot of Van der Pol oscillator for $\mathrm{a}=0.1, \mathrm{x}_{0}=\left[\begin{array}{ll}1 & 1\end{array}\right]^{\mathrm{T}}$ and time $\mathrm{t}=$ $100 \mathrm{~s}$

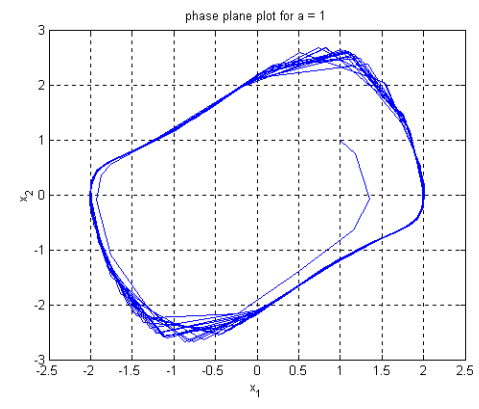

Figure 3. Phase-plane plot of Van der Pol oscillator for $\mathrm{a}=1, \mathrm{x}_{0}=\left[\begin{array}{ll}1 & 1\end{array}\right]^{\mathrm{T}}$ and time $\mathrm{t}=$

$100 \mathrm{~s}$

Simulation studies for the system with adaptive fuzzy control architecture were performed for 3 different desired trajectories $\mathrm{x}_{\mathrm{d}}$ : step input with amplitude $\mathrm{A}=2$, sinusoidal reference $\mathrm{x}_{\mathrm{ld}}=2 \cdot \sin (0.5 \Pi \mathrm{t})$ and sinusoidal reference with DC component $\mathrm{x}_{1 \mathrm{~d}}=2 \cdot \sin (0.5 \Pi \mathrm{t})+1$. All simulations were performed for $100 \mathrm{~s}$. No disturbance was introduced in the system. Cases of two different sets of initial membership functions of the fuzzy system were investigated.

The fuzzy control system parameters were: $\Lambda=5, \mathrm{~K}_{\mathrm{v}}=\operatorname{diag}\{3\}, \mathrm{K}_{\mathrm{w}}=\operatorname{diag}\{10.15\}, \mathrm{k}_{\mathrm{w}}=0.0985$, $\mathrm{K}_{\mathrm{a}}=\operatorname{diag}\{0.01\}, \mathrm{k}_{\mathrm{a}}=0.1, \mathrm{~K}_{\mathrm{b}}=\operatorname{diag}\{0.355\}, \mathrm{k}_{\mathrm{b}}=0.0282$. The fuzzy system input vector $\mathrm{z}$ was defined as $\mathrm{z}=\left[\begin{array}{llll}\mathrm{x}_{1} & \mathrm{x}_{2} & \mathrm{e}_{1} & \mathrm{e}_{2}\end{array}\right]^{\mathrm{T}}$ and membership functions were defined as Gaussian functions as described in ( 10$)$.

In subsequent subsections it is shown via simulation results that reference trajectory, changes in initial membership functions, and changes in system nonlinearity do have interesting effects on the final learned value of MFs. However, the FL system exhibits a similar type of behavior through all the analyzed cases; namely, it tries to cover the whole space in which state trajectories can be found and at the same time to focus on space in which final state trajectories rest, thus it exhibits cognitive functions.

Persistency of excitation is crucial for the proper parameter estimation in adaptive control. It describes the richness of the signal, i.e it tells if the signal data contents allows the estimation of the parameters. A vector $\mathrm{w}(\mathrm{t}) \in \mathfrak{R}^{\mathrm{n}}$ is said to be PE if there exist positive constants $\delta, \alpha_{1}$ and $\alpha_{2}$ such that ([16], [17])

$$
\alpha_{1} I \leq \int_{t_{0}}^{t_{0}+\delta} w(t) w^{T}(t) d t \leq \alpha_{2} I
$$

for all $t_{0} \geq 0$. It can be said roughly that if $w(t)$ is $n$-vector it should have at least $n$ distinct complex frequencies to be PE. For example, a sinusoidal signal is $P E$ for $n=2$ because sinusoidal signal contains two distinct complex frequencies, while step is PE only for $n=1$ because it contains only one complex frequency [17].

\subsection{Detailed Plots for Sinusoidal Reference Input}

Here are provided detailed plots in order to show the performance characteristics of the proposed FL control architecture. Also, the performance of the fuzzy controller is compared with a nonadaptive PD controller. Detailed plots are given for a sinusoidal reference input $\mathrm{x}_{1 \mathrm{~d}}=2 \cdot \sin (0.5 \Pi \mathrm{t})$ and with oscillator having parameter $\mathrm{a}=0.1$. 
The complete FL controller was compared to a standard PD controller in order to show the superiority of the FL controller. Parameters of the PD controller for comparison were: proportional gain $K_{p}=15$ and derivative gain $K_{d}=3$. The error plot in Figure 4 confirms that the error with FL control is indeed small. The solid line in Figure 4 denotes error for the system controlled by the FL controller. The error for the oscillator with the same parameters controlled by only a simplistic PD controller is marked by dashed line. It can be seen that the standard PD controller is unable to achieve small errors. Note that the FL controller has fundamentally changed the autonomous behaviour of the dynamical system illustrated in Figure 2 and Figure 3.

It can be concluded that FL control adapts to the changing nonlinear function $\mathrm{g}\left(\mathrm{x}, \mathrm{x}_{\mathrm{d}}\right)$ well. In Figure 5 are plotted $\mathrm{g}\left(\mathrm{x}, \mathrm{x}_{\mathrm{d}}\right)$ and FL approximation (output of FL controller) of $\mathrm{g}\left(\mathrm{x}, \mathrm{x}_{\mathrm{d}}\right)$. Plots of function $\mathrm{g}\left(\mathrm{x}, \mathrm{x}_{\mathrm{d}}\right)$ and its FL approximation are shown as dashed and solid lines respectively. Plots confirm that FL controller indeed approximates $\mathrm{g}\left(\mathrm{x}, \mathrm{x}_{\mathrm{d}}\right)$ well, thus it adapts to the changing nonlinear function.

Spreads and centroids of MFs are shown in Figure 6. It can be seen that the changes are smooth and relatively slow when compared with reference input. No higher frequency components can be observed in tuning of spreads and centroids of MFs. It can be also seen that spreads and centroids do not exhibit any short-term changes, but are tuned steadily over the time. An analysis in following Sections shows that spreads and centroids are indeed tuned in such way that MFs cover the whole state space in which state trajectories lay. This behaviour exhibits the long-term memory which maps the space in which the state trajectories are moving during the operation of the FL controlled system. In this way an appropriate function space is set for the linear tuning of the output layer values.

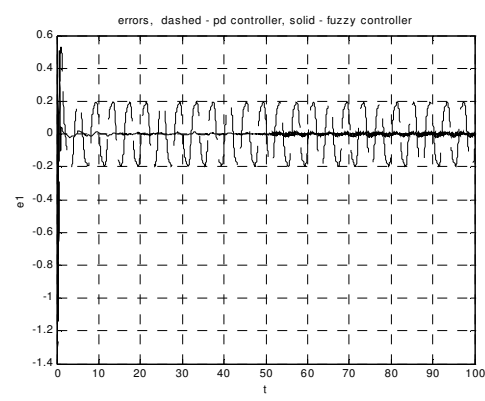

Figure 4. Error for sinusoidal input with $\mathrm{A}=2$, $\mathrm{f}=0.25 \mathrm{~Hz}, \mathrm{a}=0.1$

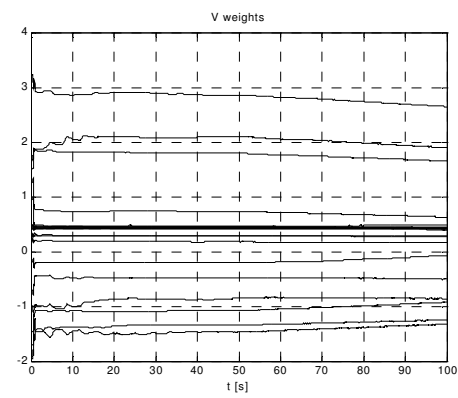

Figure 6. Spreads and centroids of membership functions for sinusoidal input with $\mathrm{A}=2, \mathrm{f}=0.25 \mathrm{~Hz}, \mathrm{a}=0.1$

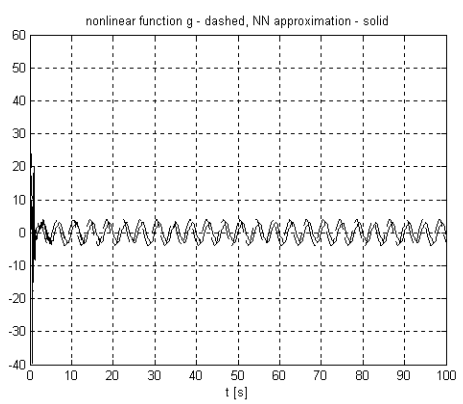

Figure 5. Nonlinear function $\mathrm{g}\left(\mathrm{x}, \mathrm{x}_{\mathrm{d}}\right)$ and the approximation of the nonlinear function $\mathrm{g}\left(\mathrm{x}, \mathrm{x}_{\mathrm{d}}\right)$ for sinusoidal input with $\mathrm{A}=2, \mathrm{f}=0.25$ $\mathrm{Hz}, \mathrm{a}=0$.

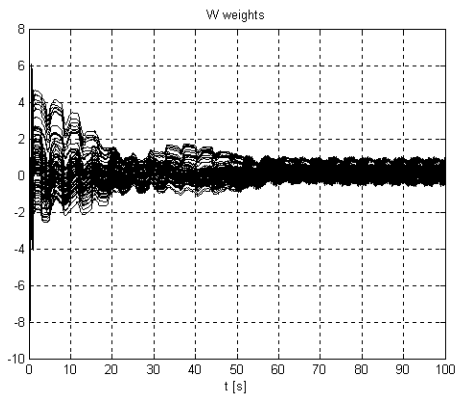

Figure 7. Output layer weights for sinusoidal input with $\mathrm{A}=2, \mathrm{f}=0.25 \mathrm{~Hz}, \mathrm{a}=0.1$ 
Output layer values of the FL controller are shown in Figure 7. In contrast to the spreads and centroids of MFs one can observe a significant higher frequency components in tuning output layer weights $\mathrm{W}$. Output layer weights exhibit the higher frequency component with the same frequency as the desired trajectory $\mathrm{x}_{\mathrm{d}}$. That is, output layer weights exhibit a short-term memory adapting themselves to fast changes. This prevents these fast changes from appearing in the error signal (plot in Figure 4.).

\subsection{Effect of Desired Trajectory on Final Values of Membership Functions}

In this subsection simulation study of the effect of different desired trajectories on the final learned values of the MFs is provided. The intention was to determine how different desired trajectories impact the final learned FL MFs.

Initial weights for all simulations in Section 5.2. are shown in Figure 8 and Figure 9. These plots are Gaussian MFs ( 9 ) of $\mathrm{x}_{2}$ vs. $\mathrm{x}_{1}$ assuming that $\mathrm{e}_{1}=0$ and $\mathrm{e}_{2}=0$.

The final MFs are shown in Figure 10 - Figure 17 in subsections 5.2.1., 5.2.2. and 5.2.3.. It can be seen from the membership functions at the end of simulation that for the different choice of $x_{d}$ we have different effects on the learned information of the FL system. Particularly useful in visualizing these effects are contour plots.

Simulation results show that FL tries to cover the space in which state trajectories are confined during the whole simulation and in the same time focus on the area that comprises final states. In another words, FL system learns the whole history of the particular run and also tries to focus more closely on the area in which final state trajectories rest. This is an exhibition of cognitive features. The FL system learns the whole history and also focuses on the more detailed task. More detailed analysis of the plots is given in subsections 5.2.1., 5.2.2. and 5.2.3..

The importance of persistent excitation (PE) for learning is also analyzed in this section.

Analysis of the plots in subsections 5.2.1., 5.2.2. and 5.2.3.shows that if signal is not PE, there is no efficient learning manifested in the FL system.

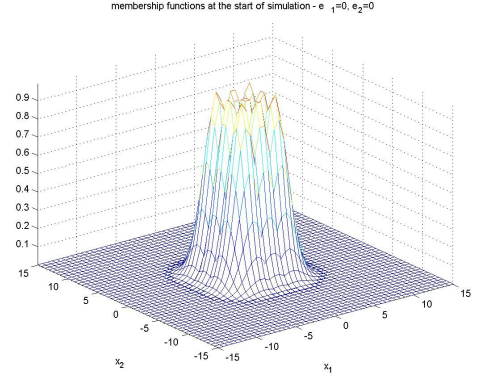

Figure 8. Membership functions at start of simulation for sinusoidal input with $\mathrm{A}=2$, $\mathrm{f}=0.25 \mathrm{~Hz}, \mathrm{a}=0.1$ assuming error vector $\mathrm{e}=0$

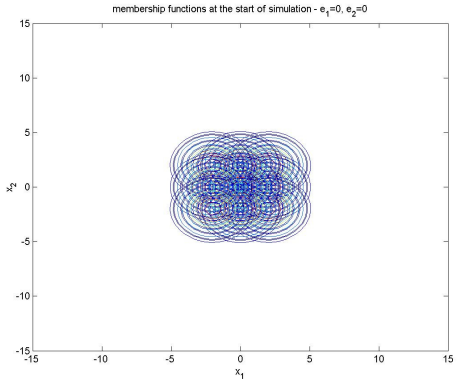

Figure 9. Membership functions at start of simulation for sinusoidal input with $\mathrm{A}=2$, $\mathrm{f}=0.25 \mathrm{~Hz}, \mathrm{a}=0.1$ assuming error vector $\mathrm{e}=0-$ contour plot

\subsubsection{Sinusoidal Reference Input}

Membership functions at the end of simulation for sinusoidal reference input in Figure 10 have a very different shape than the initial membership functions in Figure 8. Also they cover a broader area than the original MFs, but with the area covered by initial MFs almost completely included (Figure 11). In fact, analysis of MF contour plots over time shows that MFs "stretch" in order to cover the region in which state trajectories are changing with time (not all plots are given here due to space constraints).. It can be said that FL input layer membership functions 
dynamically focus to cover the area in which state trajectories are moving over time. However, the final MFs cover much broader area than needed for final state trajectories. It seems that MFs do not focus only exactly on the area in which the final state trajectories are lying, but cover the area that includes states trajectories during the whole simulation. This reveals the presence of the cognitive focusing of awareness both of long-term memory and short-term memory.

It is important to note that the sinusoidal reference is PE for the given plant (Van der Pol oscillator) in general and for the nonlinear function $\mathrm{f}(\mathrm{x})$ in particular. From the equation $(26)$ it can be seen that Van der Pol oscillator is a system defined in $\mathfrak{R}^{2}$. Nonlinear function $f(x)=-\alpha\left(x_{1}^{2}-1\right) x_{2}-x_{1}$ is also clearly defined in $\mathfrak{R}^{2}$. Final MFs for this case, as stated before, clearly show the cognitive learning abilities of FL system. A different situation will occur with the step reference as it will be shown in the following subsection.

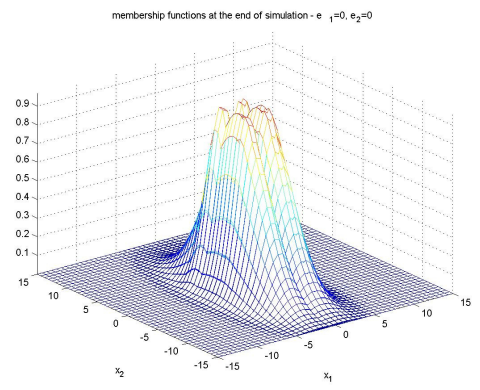

Figure 10. Membership functions at the end of simulation for sinusoidal input with $\mathrm{A}=2$, $\mathrm{f}=0.25 \mathrm{~Hz}, \mathrm{a}=0.1$ assuming error vector $\mathrm{e}=0$

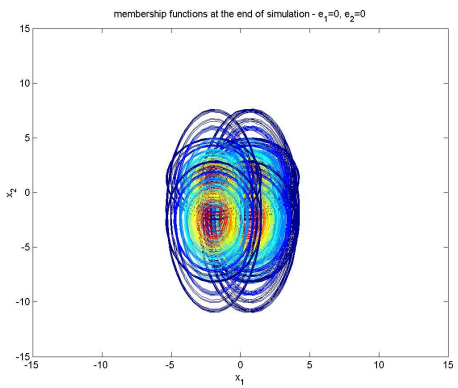

Figure 11. Membership functions at the end of simulation for sinusoidal input with $\mathrm{A}=2$, $\mathrm{f}=0.25 \mathrm{~Hz}, \mathrm{a}=0.1$ assuming error vector $\mathrm{e}=0-$ contour plot

\subsubsection{Step Reference Input}

Membership functions at the end of the simulation for the step reference input are shown in Figure 12 and Figure 13. From Figure 13 one can note that membership functions at the end of simulation cover slightly smaller area than the initial membership functions in Figure 8. From Figure 12 it can be seen that there are otherwise no significant changes in MFs shape. There are no significant changes in the shape of the final MFs when compared with initial MFs. Also, final MFs are not centered around the final state trajectories (which are here just the point $\mathrm{x}=[2$ $0]^{\mathrm{T}}$ ). That leads to the conclusion that no significant learning was present in this situation. It is important to note that step reference is not a PE signal for the system dealt with here. PE in simpler terms means that all the system modes should be excited for the proper parameter identification. That is not the case here and this fact is shown by the absence of any more significant changes in the final MFs when compared with the initial MFs. Results lead to the conclusion that for meaningful cognitive learning, PE of the desired signal imposed on the system is very important, if not crucial. These notions will be stressed in the case of erroneous initial MFs guess in Section 5.3. 


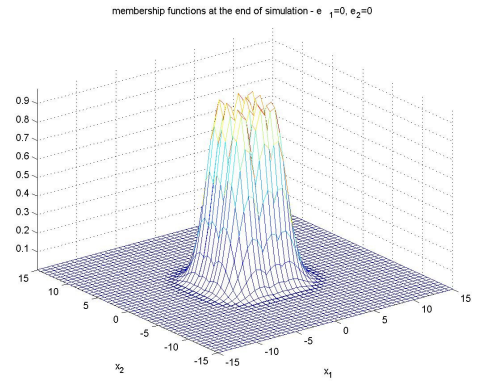

Figure 12. Membership functions at the end of simulation for step input with $\mathrm{A}=2, \mathrm{a}=0.1$ assuming error vector $\mathrm{e}=0$

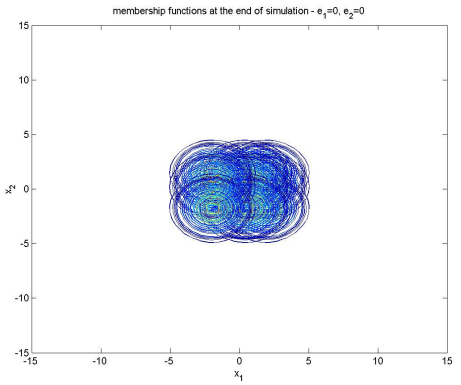

Figure 13. Membership functions at the end of simulation for step input with $\mathrm{A}=2, \mathrm{a}=0.1$ assuming error vector $\mathrm{e}=0$ - contour plot

\subsubsection{Sinusoidal Reference Input with DC Offset}

The third analyzed case was for sinusoidal reference input with DC component. Final MFs are shown in Figure 14 and Figure 15. From Figure 14 it can be seen that there are some changes in shape of MFs. From Figure 15 it can be seen that final MFs cover approximately the same area as initial MFs, although a little bit shifted toward the area covered by the final state trajectories. The shift toward the area covered by final state trajectories suggests that input layer MFs are indeed trying to focus on area that covers state trajectories final state trajectories, but also to cover the state trajectories during the whole simulation. The learning can be observed. The reference input $\mathrm{x}_{\mathrm{d}}$ is PE in this case.

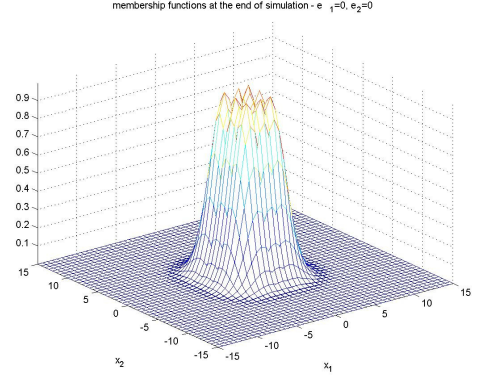

Figure 14. Membership functions at the end of simulation for sinusoidal input with $\mathrm{A}=2$, $\mathrm{f}=0.25 \mathrm{~Hz}, \mathrm{a}=0.1$ and $\mathrm{DC}$ component $\mathrm{DC}=1$ assuming error vector $\mathrm{e}=0$

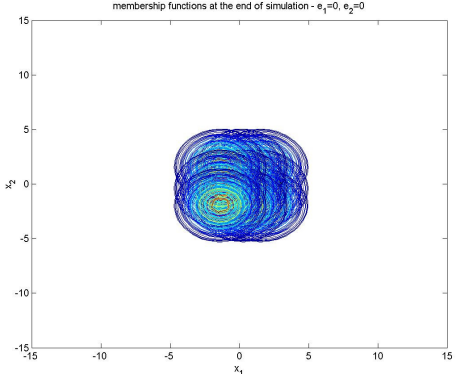

Figure 15. Membership functions at the end of simulation for sinusoidal input with $\mathrm{A}=2$, $\mathrm{f}=0.25 \mathrm{~Hz}, \mathrm{a}=0.1$ and $\mathrm{DC}$ component $\mathrm{DC}=1$ assuming error vector $\mathrm{e}=0$ - contour plot

\subsection{Effect of Shifted Initial Membership Functions on Final Membership Functions}

In this subsection is provided a simulation study of the effect of shifted initial MFs on final values of MFs. The intention of the study was to determine how initial values of the FL parameters impact the final FL MFs. This reveals the effect of initial incorrect information on the final information learned by the FL system.

Initial weights for all simulations in Section 5.3, assuming that errors are 0, are shown in Figure 16 and Figure 17. Initial states $x_{0}$ are marked with "x" in Figure 22. It is important to note that the initial system states lay outside area covered by these initial FL MFs (i.e. value of MF's in that area is very small). 
Final MFs are shown in Figure 18 - Figure 23 in subsections 5.3.1, 5.3.2. and 5.3.3.. Results show that initial MFs do have significant effect on final MFs. The FL system does focus on the final state trajectories area and does covers the whole state space, but final MFs are in general different than in Section 5.2. More detailed argument is given in subsections 5.3.1, 5.3.2. and 5.3.3.. In addition, an effect of the excitation signal that is not PE on the learning ability of the FL system is illustrated in subsection 5.3.2.

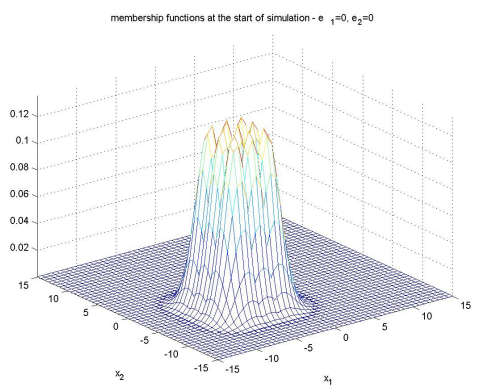

Figure 16. Membership functions with shifted centroids at start of simulation for sinusoidal input with $\mathrm{A}=2, \mathrm{f}=0.25 \mathrm{~Hz}, \mathrm{a}=0.1$ assuming error vector $\mathrm{e}=0$

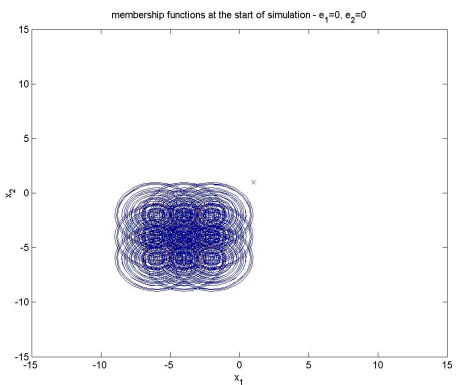

Figure 17. Membership functions with shifted centroids at start of simulation for sinusoidal input with $\mathrm{A}=2, \mathrm{f}=0.25 \mathrm{~Hz}, \mathrm{a}=0.1$ assuming error vector $\mathrm{e}=0$ - contour plot

\subsubsection{Sinusoidal Reference Input}

Membership functions at the end of simulation in Figure 18 for sinusoidal reference input have a different shape than the initial membership functions in Figure 16. They cover broader area than original MFs. It can be also noted that the area covered by MFs at the end Figure 18 is shifted toward the area covered by the final MFs in the case when the initial centroids were not shifted. Also, the change in shape is not as much accented as in Section 5.2. However, the final MFs are significantly different than for the same input in the case when initial MF centroids were not shifted. Effect of initial values of MFs can be clearly seen.

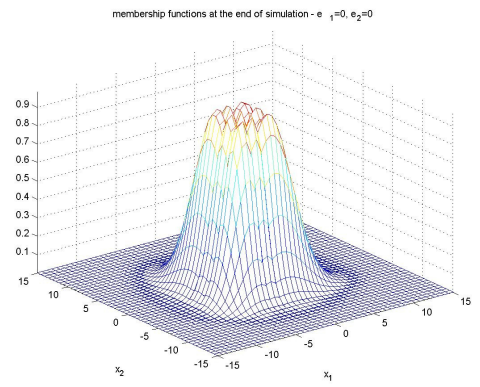

Figure 18. Membership functions with shifted centroids at the end of simulation for sinusoidal input with $\mathrm{A}=2, \mathrm{f}=0.25 \mathrm{~Hz}, \mathrm{a}=0.1$ assuming error vector $\mathrm{e}=0$

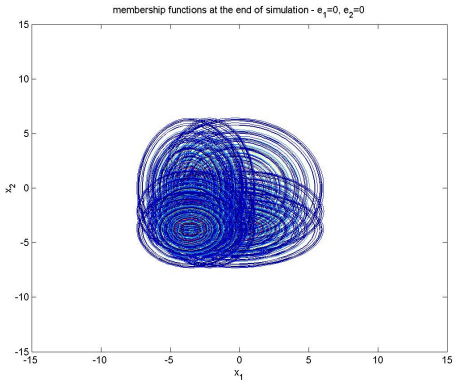

Figure 19. Membership functions with shifted centroids at the end of simulation for sinusoidal input with $\mathrm{A}=2, \mathrm{f}=0.25 \mathrm{~Hz}, \mathrm{a}=0.1$ assuming error vector $\mathrm{e}=0$ - contour plot

It appears that "preset knowledge" of FL system has an important effect on final values of MFs. This result leads to a conclusion that while FL system will try to cover the space inside which state trajectories are comprised and in the same time to focus on the final state trajectories area, the final MFs will be affected by initial MF's. In another words, a different "state knowledge" 
will be reached depending on the initial MFs while trying to reach the same goal. Mathematically speaking, this illustrates the fact that in the case when no unique solution exists, the final state of FL logic system will depend very much on it's initial state, converging to a local minimum. The reference input $x_{d}$ is PE and the difference between final MFs and initial MFs is clear. This illustrates the fact that the FL system did indeed exhibit a learning ability.

\subsubsection{Step Reference Input}

Membership functions at the end of simulation for step reference input are shown in Figure 20 and Figure 21. The shape of membership functions did not change much. From Figure 21 one can note that membership functions at the end of simulation are shifted towards the area covered by final MFs when initial centroids are not shifted. Again, FL system tries to focus on the area where state trajectories lay. Phase-plane shows that state trajectories are covered by final MFs. Also, final MF are shifted toward space in which final state trajectories lay. Again, final MFs are different than in case of original MFs which shows the same effect on different initial functions as for sinusoidal reference. However, the final MFs are not centered over the final state point, showing that FL system did not adapt itself sufficiently to estimate the nonlinearities in the controlled plant. During the simulation it was observed that the time needed for MFs to tune itself to the proper area in state space was rather long, much longer than in case of the sinusoidal reference signal. This points to an absence of short-term memory, because the system is not sufficiently stimulated and learning is slow. Step input is not a persistently excited (PE) signal, but the FL controller is still able to control the system.

However, it is important to point out that while the system exhibits some form of learning ability, the final states are just barely covered by the final MFs. Every additional change in the signal will have a strong effect and a new long learning process will be needed. This illustrates the importance of PE of the reference signal in the learning process. PE affects very strongly the short-term memory. Lack of PE makes it impossible to learn how to respond to fast changes, while it does allow very slow adaptation to the point where the state trajectories are covered. It can be said that cognitive features of the FL system cannot be observed in this case.



Figure 20. Membership functions with shifted centroids at the end of simulation for step input with $\mathrm{A}=2, \mathrm{a}=0.1$ assuming error vector $\mathrm{e}=0$

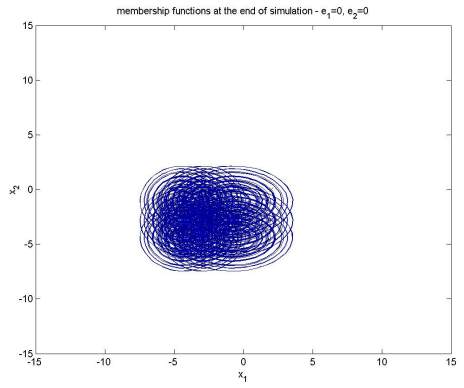

Figure 21. Membership functions with shifted centroids at the end of simulation for step input with $\mathrm{A}=2, \mathrm{a}=0.1$ assuming error vector $\mathrm{e}=0-$ contour plot

\subsubsection{Sinusoidal Reference Input with DC Offset}

The third analyzed case was for sinusoidal reference input with DC component. Final MFs are shown in Figure 22 and Figure 23. From Figure 22 it can be seen that there no significant changes in shape of MFs. From Figure 23 it can be seen that final MFs are shifted toward the area covered by final MFs in the case when initial centroids were not shifted. In this case there was no significant difference in final MFs from Section 5.2. The FL system tries to focus on the 
area where final state trajectories lay and to cover the whole state space in the same time. This reference signal is PE and it seems that memory functions have been restored. Also, the learning process is much faster than in the case of purely step reference.

Also, from the plot in Figure 23 it can be seen that final MFs converge to approximately the same area as in Section 5.2. This shows the very important ability of the FL controller to compensate for eronous initial information as long as the control task is sufficiently stimulating. Again, the cognitive features of the FL logic controller are illustrated.

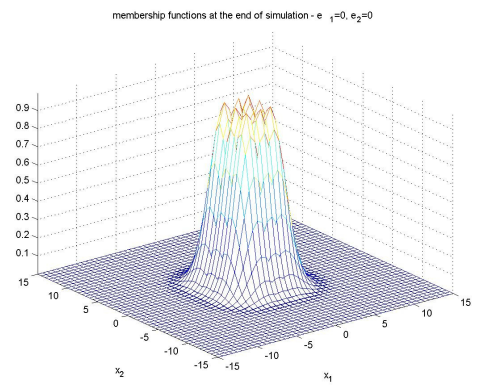

Figure 22. Membership functions with shifted centroids at the end of simulation for sinusoidal input with $\mathrm{A}=2, \mathrm{f}=0.25 \mathrm{~Hz}, \mathrm{a}=0.1$ and $\mathrm{DC}$ component $\mathrm{DC}=1$ assuming error vector $\mathrm{e}=0$

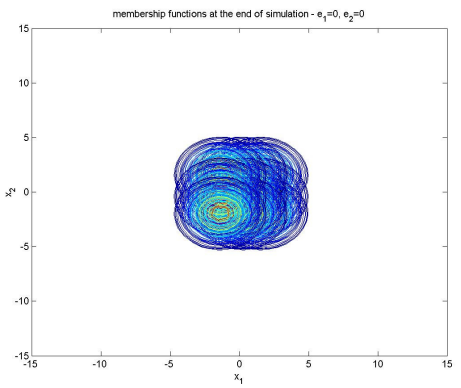

Figure 23. Membership functions with shifted centroids at the end of simulation for sinusoidal input with $\mathrm{A}=2, \mathrm{f}=0.25 \mathrm{~Hz}, \mathrm{a}=0.1$ and $\mathrm{DC}$ component $\mathrm{DC}=1$ assuming error vector $\mathrm{e}=0-$ contour plot

\subsection{Effect of Change of System Parameters on Final Membership Functions}

The system parameter changes are examined for the same initial MFs as in Section 5.2. Here, we set parameter $\mathrm{a}=1$ and performed the simulation with the sinusoidal reference input.

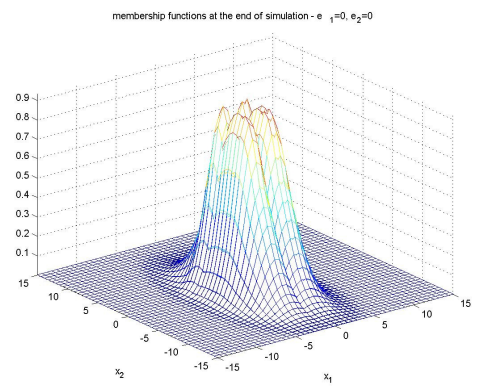

Figure 24. Membership functions at the end of simulation for sinusoidal input with $\mathrm{A}=2$, $\mathrm{f}=0.25 \mathrm{~Hz}, \mathrm{a}=1$ assuming error vector $\mathrm{e}=0$

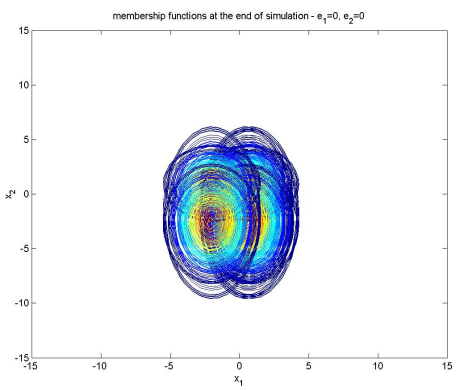

Figure 25. Membership functions at the end of simulation for sinusoidal input with $\mathrm{A}=2$, $\mathrm{f}=0.25 \mathrm{~Hz}, \mathrm{a}=1$ assuming error vector $\mathrm{e}=0-$ contour plot

It can be seen from membership functions at the end of simulation that this case does not appreciably differ from the case of $a=0.1$. That is, the final MF's do not depend on system parameter variations. In fact, changes in the value of the system parameter "a" were compensated by different behaviour of the control representative values $\mathrm{W}$. The short-term 
memory seems to change with different system parameter values. The long-term memory depends more on the desired reference signal.

\section{Conclusion}

A fuzzy logic control architecture is described in the paper. A detailed stability proof is given. The proposed FL control algorithm does not require any assumptions on the initial parameters of FL controller for the system to be stable. The performance of the FL controller is studied in detail using simulation studies. Effects of changes in initial FL parameters, plant nonlinearity, and different reference trajectories on the final FL MFs were investigated with the intention of drawing some conclusions on how the learned MFs adapt to changing environments.

Simulation results have shown the following interesting features. First, the FL controller adapts well to different reference trajectories as long as the excitation is persistently exciting. It was observed that input layer MFs are changing in such a way that the whole state space in which plant states are contained is covered by MFs, but also that MFs are trying to put more weight on approximating plant states at their steady trajectories after the transient is finished if the excitation is PE. The controlled system is stable even when excitation signal is not PE (which confirms the results of the stability proof), but in this case only the partial long-term memory effects can be recognized. This shows the significance of PE in the focusing of awareness and realizing the cognitive functions of the FL system. It can be said that if the excitation signal (reference or disturbance) is not rich enough, the learning and cognition are affected by the lack of stimulus (i.e. not all modes are excited), and the adaptation to the changing environment with the respect to the history is poor. The FL system does not acquire enough knowledge. Shortterm memory functions are also not active in cases when excitation is not PE. That may cause the problems in case FL is used in control of real systems because controller will not adapt fast enough and may cause diminished quality of controlled system response. Further work is aimed to find FL control systems with improved cognition abilities.

\section{Appendix - Proof of Theorem}

Using equations ( 2 ), ( 3 ) and ( 4 ) the dynamics of the performance measure signal ( 5 ) can be written as:

$$
\dot{\mathrm{r}}=\mathrm{g}\left(\mathrm{x}, \mathrm{x}_{\mathrm{d}}\right)-\mathrm{u}(\mathrm{t})-\mathrm{d}(\mathrm{t})
$$

where $\mathrm{g}\left(\mathrm{x}, \mathrm{x}_{\mathrm{d}}\right)$ is a complex nonlinear function of the state and desired trajectory vectors $\mathrm{x}$ and $\mathrm{x}_{\mathrm{d}}$, respectively. Note that this function includes the original system unknown nonlinear function $f(x)$. According to the approximation properties of fuzzy logic systems, the continuous nonlinear function $\mathrm{g}\left(\mathrm{x}, \mathrm{x}_{\mathrm{d}}\right)$ in (29) can be represented as

$$
\mathrm{g}\left(\mathrm{x}, \mathrm{x}_{\mathrm{d}}\right)=\mathrm{W}^{\mathrm{T}} \Phi(\mathrm{z}, \mathrm{a}, \mathrm{b})+\varepsilon(\mathrm{z}) \text {, }
$$

where $\mathrm{z}$ is the input vector to the fuzzy system $\varepsilon(\mathrm{z})$ is bounded by a known constant $\varepsilon_{\mathrm{N}}$. The ideal weights $\mathrm{W}$ and spreads and centroids $\mathrm{a}$ and $\mathrm{b}$ that approximate $\mathrm{g}(\cdot)$ are unknown.

Let the control input $u(t)$ be given by

$$
\mathrm{u}(\mathrm{t})=+\mathrm{K}_{\mathrm{v}} \mathrm{r}+\hat{\mathrm{g}}\left(\mathrm{x}, \mathrm{x}_{\mathrm{d}}\right)
$$

where $\hat{\mathrm{g}}\left(\mathrm{x}, \mathrm{X}_{\mathrm{d}}\right)$ is provided by the fuzzy system, the control gain matrix is $\mathrm{K}_{\mathrm{v}}=\mathrm{K}_{\mathrm{v}}^{\mathrm{T}}>0$. 
Let the fuzzy functional estimate for the continuous nonlinear function $\mathrm{g}\left(\mathrm{x}, \mathrm{x}_{\mathrm{d}}\right)$ be

$$
\hat{\mathrm{g}}\left(\mathrm{x}, \mathrm{x}_{\mathrm{d}}\right)=\hat{\mathrm{W}}^{\mathrm{T}} \Phi(\mathrm{z}, \hat{\mathrm{a}}, \hat{\mathrm{b}}) \text {. }
$$

Then, filtered error dynamics ( 29 ) can be rewritten as

$$
\dot{\mathrm{r}}=-\mathrm{K}_{\mathrm{v}} \mathrm{r}+\tilde{\mathrm{g}}\left(\mathrm{x}, \mathrm{x}_{\mathrm{d}}\right)-\mathrm{d}(\mathrm{t}),
$$

where the functional estimation error is defined as $\tilde{g}\left(x, x_{d}\right)=g\left(x, x_{d}\right)-\hat{g}\left(x, x_{d}\right)$.

Now, using ( 30 ) and ( 32 ), equation ( 33 ) can be written as

$$
\dot{\mathrm{r}}=-\mathrm{K}_{\mathrm{v}} \mathrm{r}+\mathrm{W}^{\mathrm{T}} \Phi(\mathrm{z}, \mathrm{a}, \mathrm{b})-\hat{\mathrm{W}}^{\mathrm{T}} \Phi(\mathrm{z}, \hat{\mathrm{a}}, \hat{\mathrm{b}})+\mathrm{d}(\mathrm{t})+\varepsilon .
$$

Define:

$$
\begin{aligned}
& \tilde{\mathrm{W}}=\mathrm{W}-\hat{\mathrm{W}}, \tilde{\Phi}=\Phi(\mathrm{z}, \tilde{\mathrm{a}}, \tilde{\mathrm{b}}), \hat{\Phi}=\Phi(\mathrm{z}, \hat{\mathrm{a}}, \hat{\mathrm{b}}), \\
& \tilde{\mathrm{a}}=\mathrm{a}-\hat{\mathrm{a}}, \quad \tilde{\mathrm{b}}=\mathrm{b}-\hat{\mathrm{b}} .
\end{aligned}
$$

Then,

$$
\mathrm{W}^{\mathrm{T}} \Phi-\hat{\mathrm{W}}^{\mathrm{T}} \hat{\Phi}=\tilde{\mathrm{W}}^{\mathrm{T}} \tilde{\Phi}+\hat{\mathrm{W}}^{\mathrm{T}} \tilde{\Phi}+\tilde{\mathrm{W}}^{\mathrm{T}} \hat{\Phi}
$$

Now, Taylor expansion of $\Phi$ can be written as

$$
\Phi=\hat{\Phi}+\mathrm{A} \tilde{a}+\mathrm{B} \tilde{b}+\mathrm{H},
$$

where $\mathrm{A}$ and $\mathrm{B}$ are suitable jacobians and $\mathrm{H}$ represents higher order terms.

$$
\begin{aligned}
& A=\left\langle\left.\frac{\partial \Phi}{\partial a}\right|_{a=\hat{a}, b=\hat{b}} .\right. \\
& B=\left\langle\left.\frac{\partial \Phi}{\partial b}\right|_{a=\hat{a}, b=\hat{b}} .\right.
\end{aligned}
$$

The explicit expression of Jacobians for Gaussian membership functions along the 1-th rule and $i$-th input dimension is given by

$$
\begin{gathered}
\frac{\partial \Phi_{i_{j}}}{\partial a_{i_{1} i_{2} \ldots i_{n}}}=2 \Phi_{i_{j}}\left(1-\Phi_{i_{j}}\right)\left(x_{j}-b_{i_{1} i_{2} \ldots i_{n}}\right)^{2} \cdot a_{i_{1} i_{2} \ldots i_{n}}, \\
\frac{\partial \Phi_{i_{j}}}{\partial b_{i_{1} i_{2} \ldots i_{n}}}=2 \Phi_{i_{j}}\left(1-\Phi_{i_{j}}\right)\left(x_{j}-b_{i_{1} i_{2} \ldots i_{n}}\right) \cdot a_{i_{1} i_{2} \ldots i_{n}}^{2} \cdot
\end{gathered}
$$

Introduce ( 36 ) into ( 34 ):

$$
\dot{\mathrm{r}}=-\mathrm{K}_{\mathrm{v}} \mathrm{r}+\tilde{\mathrm{W}}^{\mathrm{T}} \tilde{\boldsymbol{\Phi}}+\hat{\mathrm{W}}^{\mathrm{T}} \tilde{\boldsymbol{\Phi}}+\tilde{\mathrm{W}}^{\mathrm{T}} \hat{\boldsymbol{\Phi}}+\mathrm{d}+\varepsilon .
$$

With Taylor expansion ( 37 ) equation ( 42 ) can be written as

$$
\dot{\mathrm{r}}=-\mathrm{K}_{\mathrm{v}} \mathrm{r}+\tilde{\mathrm{W}}^{\mathrm{T}}(\mathrm{A} \tilde{\mathrm{a}}+\mathrm{B} \tilde{\mathrm{b}}+\mathrm{H})+\hat{\mathrm{W}}^{\mathrm{T}}(\mathrm{A} \tilde{\mathrm{a}}+\mathrm{B} \tilde{\mathrm{b}}+\mathrm{H})+\tilde{\mathrm{W}}^{\mathrm{T}} \hat{\Phi}+\mathrm{d}+\varepsilon .
$$

Define Lyapunov candidate

$$
\mathrm{L}=\frac{1}{2} \mathrm{r}^{\mathrm{T}} \mathrm{r}+\frac{1}{2} \operatorname{tr}\left(\tilde{\mathrm{W}}^{\mathrm{T}} \mathrm{K}_{\mathrm{W}}^{-1} \tilde{\mathrm{W}}\right)+\frac{1}{2} \tilde{\mathrm{a}}^{\mathrm{T}} \mathrm{K}_{\mathrm{a}}^{-1} \tilde{\mathrm{a}}+\frac{1}{2} \tilde{\mathrm{b}}^{\mathrm{T}} \mathrm{K}_{\mathrm{b}}^{-1} \tilde{\mathrm{b}},
$$

where $\mathrm{K}_{\mathrm{W}}, \quad \mathrm{K}_{\mathrm{a}}, \quad \mathrm{K}_{\mathrm{b}}$ and $\mathrm{K}_{\mathrm{c}}$ are design matrices and $\mathrm{K}_{\mathrm{W}}=\mathrm{K}_{\mathrm{W}}^{\mathrm{T}}>0 ; \mathrm{K}_{\mathrm{a}}=\mathrm{K}_{\mathrm{a}}^{\mathrm{T}}>0 ; \mathrm{K}_{\mathrm{b}}=\mathrm{K}_{\mathrm{b}}^{\mathrm{T}}>0$.

Differentiating ( 44 ) yields

$$
\dot{\mathrm{L}}=\mathrm{r}^{\mathrm{T}} \dot{\mathrm{r}}+\operatorname{tr}\left(\tilde{\mathrm{W}}^{\mathrm{T}} \mathrm{K}_{\mathrm{W}}^{-1} \dot{\tilde{\mathrm{W}}}\right)+\tilde{\mathrm{a}}^{\mathrm{T}} \mathrm{K}_{\mathrm{a}}^{-1} \dot{\tilde{\mathrm{a}}}+\tilde{\mathrm{b}}^{\mathrm{T}} \mathrm{K}_{\mathrm{b}}^{-1} \dot{\tilde{\mathrm{b}}} .
$$


From ( 35 ) it is clear that:

$$
\dot{\tilde{a}}=-\dot{\hat{\mathrm{a}}}, \quad \dot{\tilde{\mathrm{b}}}=-\dot{\hat{\mathrm{b}}}, \quad \dot{\tilde{\mathrm{W}}}=-\dot{\hat{\mathrm{W}}}
$$

Introduce ( 46 ) into ( 45 ):

$$
\dot{\mathrm{L}}=\mathrm{r}^{\mathrm{T}} \dot{\mathrm{r}}+\operatorname{tr}\left(-\tilde{\mathrm{W}}^{\mathrm{T}} \mathrm{K}_{\mathrm{W}}^{-1} \dot{\hat{\mathrm{W}}}\right)-\tilde{\mathrm{a}}^{\mathrm{T}} \mathrm{K}_{\mathrm{a}}^{-1} \dot{\hat{\mathrm{a}}}-\tilde{\mathrm{b}}^{\mathrm{T}} \mathrm{K}_{\mathrm{b}}^{-1} \dot{\hat{\mathrm{b}}} .
$$

Substituting ( 43 ) into ( 47 ) yields

$$
\begin{aligned}
\dot{\mathrm{L}} & =-\mathrm{r}^{\mathrm{T}} \mathrm{K}_{\mathrm{v}} \mathrm{r}+\mathrm{r}^{\mathrm{T}} \tilde{\mathrm{W}}^{\mathrm{T}}(\mathrm{A} \tilde{\mathrm{a}}+\mathrm{B} \tilde{\mathrm{b}}+\mathrm{H})+\mathrm{r}^{\mathrm{T}} \hat{\mathrm{W}}^{\mathrm{T}}(\mathrm{A} \tilde{\mathrm{a}}+\mathrm{B} \tilde{\mathrm{b}}+\mathrm{H})+\mathrm{r}^{\mathrm{T}} \tilde{\mathrm{W}}^{\mathrm{T}} \hat{\Phi} \\
& +\mathrm{r}^{\mathrm{T}}(\mathrm{d}+\varepsilon)+\operatorname{tr}\left(-\tilde{\mathrm{W}}^{\mathrm{T}} \mathrm{K}_{\mathrm{W}}^{-1} \dot{\hat{\mathrm{W}}}\right)-\tilde{\mathrm{a}}^{\mathrm{T}} \mathrm{K}_{\mathrm{a}}^{-1} \dot{\hat{\mathrm{a}}}-\tilde{\mathrm{b}}^{\mathrm{T}} \mathrm{K}_{\mathrm{b}}^{-1} \dot{\hat{b}} .
\end{aligned}
$$

Collecting appropriate terms yields

$$
\begin{aligned}
\dot{L} & =-r^{T} K_{v} r+r^{T} \tilde{W}^{T}(\hat{\Phi}-A \hat{a}-B \hat{b})+\operatorname{tr}\left(-\tilde{W}^{T} K_{W}^{-1} \dot{\hat{W}}\right)+\tilde{a}^{T}\left(A^{T} \hat{W} r-K_{a}^{-1} \dot{\hat{a}}\right)+r^{T} W^{T} H \\
& +\tilde{b}^{T}\left(B^{T} \hat{W} r-K_{b}^{-1} \dot{\hat{b}}\right)+r^{T} \tilde{W}^{T}(A a+B b)+r^{T}(d+\varepsilon) .
\end{aligned}
$$

Introducing tuning laws ( 23 ), ( 24 ) and ( 25 ) into ( 49 ) yields

$$
\begin{aligned}
\dot{\mathrm{L}}= & -\mathrm{r}^{\mathrm{T}} \mathrm{K}_{\mathrm{v}} \mathrm{r}+\mathrm{k}_{\mathrm{w}}\|\mathrm{r}\| \cdot \operatorname{tr}\left(\tilde{\mathrm{W}}^{\mathrm{T}} \hat{\mathrm{W}}\right)+\mathrm{k}_{\mathrm{a}}\|\mathrm{r}\| \tilde{\mathrm{a}}^{\mathrm{T}} \hat{\mathrm{a}}+\mathrm{k}_{\mathrm{b}}\|\mathrm{r}\| \tilde{\mathrm{b}}^{\mathrm{T}} \hat{\mathrm{b}} \\
& +\mathrm{r}^{\mathrm{T}} \mathrm{W}^{\mathrm{T}} \mathrm{H}+\mathrm{r}^{\mathrm{T}} \tilde{\mathrm{W}}^{\mathrm{T}}(\mathrm{Aa}+\mathrm{Bb})+\mathrm{r}^{\mathrm{T}}(\mathrm{d}+\varepsilon) .
\end{aligned}
$$

For Gaussian FBFs there exists the following bound [4]:

$$
\left\|r^{\mathrm{T}} \mathrm{W}^{\mathrm{T}} \mathrm{H}+\mathrm{r}^{\mathrm{T}} \tilde{\mathrm{W}}^{\mathrm{T}}(\mathrm{Aa}+\mathrm{Bb})\right\| \leq\|\mathrm{r}\| \cdot\left(\mathrm{c}_{0}+\mathrm{c}_{1}\|\tilde{\mathrm{W}}\|+\mathrm{c}_{2}\|\tilde{\mathrm{a}}\|+\mathrm{c}_{3}\|\tilde{\mathrm{b}}\|\right) \cdot
$$

Now, with ( 51 ) and with assumptions 1 and 3 from Section 0 xxxx, and using the facts $\operatorname{tr}\left(\tilde{\mathrm{W}}^{\mathrm{T}} \hat{\mathrm{W}}\right) \leq\|\tilde{\mathrm{W}}\| \cdot\left(\mathrm{W}_{\mathrm{M}}-\|\tilde{\mathrm{W}}\|\right) \quad([14]), \quad \tilde{\mathrm{a}}^{\mathrm{T}} \hat{\mathrm{a}} \leq\|\tilde{\mathrm{a}}\| \cdot\left(\mathrm{a}_{\mathrm{M}}-\|\tilde{\mathrm{a}}\|\right), \quad \tilde{\mathrm{b}}^{\mathrm{T}} \hat{\mathrm{b}} \leq\|\tilde{\mathrm{b}}\| \cdot\left(\mathrm{b}_{\mathrm{M}}-\|\tilde{\mathrm{b}}\|\right)$, from ( 50 ) the following inequality can be obtained:

$$
\begin{aligned}
\dot{\mathrm{L}} \leq & -\mathrm{K}_{\mathrm{vmin}}\|\mathrm{r}\|^{2}+\mathrm{k}_{\mathrm{w}}\|\mathrm{r}\| \cdot\left[\|\tilde{\mathrm{W}}\|\left(\mathrm{W}_{\mathrm{M}}-\|\tilde{\mathrm{W}}\|\right)\right]+\mathrm{k}_{\mathrm{a}}\|\mathrm{r}\| \cdot\left[\left[\tilde{\mathrm{a}} \|\left(\mathrm{a}_{\mathrm{M}}-\|\tilde{\mathrm{a}}\|\right)\right]+\mathrm{k}_{\mathrm{b}}\|\mathrm{r}\| \cdot\|\tilde{\mathrm{b}}\|\left(\mathrm{b}_{\mathrm{M}}-\|\tilde{\mathrm{b}}\|\right)\right] \\
& +\|\mathrm{r}\| \cdot\left(\mathrm{c}_{0}+\mathrm{c}_{1}\|\tilde{\mathrm{W}}\|+\mathrm{c}_{2}\|\tilde{\mathrm{a}}\|+\mathrm{c}_{3}\|\tilde{\mathrm{b}}\|+\mathrm{b}_{\mathrm{d}}+\varepsilon_{\mathrm{N}}\right),
\end{aligned}
$$

where $\mathrm{K}_{\mathrm{vmin}}$ is the minimum singular value of $\mathrm{K}_{\mathrm{v}}$. From ( 52 ) it is easy to obtain ( 53 ):

$$
\begin{gathered}
\left.\dot{L} \leq-\|r\|\left\{K_{v \min }\|r\|-k_{w} \cdot\left[\|\tilde{W}\|\left(W_{M}-\|\tilde{W}\|\right)\right]-k_{a} \cdot\left[\|\tilde{a}\|\left(a_{M}-\|\tilde{a}\|\right)\right]-k_{b} \cdot\|\tilde{b}\|\left(b_{M}-\|\tilde{b}\|\right)\right]\right\} \\
+\|r\|\left[D+c_{1}\|\tilde{W}\|+c_{2}\|\tilde{a}\|+c_{3}\|\tilde{b}\|\right], \\
\mathrm{D}=\mathrm{c}_{0}+\mathrm{b}_{\mathrm{d}}+\varepsilon_{\mathrm{N}} .
\end{gathered}
$$

Let us define auxiliary variables $D_{w}, D_{a}$ and $D_{b}$,

$$
\mathrm{D}_{\mathrm{w}}=\frac{\mathrm{k}_{\mathrm{W}} \mathrm{W}_{\mathrm{M}}+\mathrm{c}_{1}}{2 \sqrt{\mathrm{k}_{\mathrm{w}}}}, \mathrm{D}_{\mathrm{a}}=\frac{\mathrm{k}_{\mathrm{a}} \mathrm{a}_{\mathrm{M}}+\mathrm{c}_{2}}{2 \sqrt{\mathrm{k}_{\mathrm{a}}}}, \mathrm{D}_{\mathrm{b}}=\frac{\mathrm{k}_{\mathrm{b}} \mathrm{b}_{\mathrm{M}}+\mathrm{c}_{3}}{2 \sqrt{\mathrm{k}_{\mathrm{b}}}} \text {. }
$$

Using ( 54 ) and completing squares in ( 53 ) results in

$$
\dot{\mathrm{L}} \leq-\|\mathrm{r}\|\left[\mathrm{K}_{\mathrm{v} \min }\|\mathrm{r}\|+\left(\sqrt{\mathrm{k}_{\mathrm{w}}} \cdot\|\tilde{\mathrm{W}}\|-\mathrm{D}_{\mathrm{w}}\right)^{2}-\mathrm{D}_{\mathrm{w}}^{2}+\left(\sqrt{\mathrm{k}_{\mathrm{a}}} \cdot\|\tilde{\mathrm{a}}\|-\mathrm{D}_{\mathrm{a}}\right)^{2}-\mathrm{D}_{\mathrm{a}}^{2}+\left(\sqrt{\mathrm{k}_{\mathrm{b}}} \cdot\|\tilde{\mathrm{b}}\|-\mathrm{D}_{\mathrm{b}}\right)^{2}-\mathrm{D}_{\mathrm{b}}^{2}-\mathrm{I}\right.
$$

Let us define auxiliary variable $\Delta$,

$$
\Delta=\mathrm{D}_{\mathrm{w}}^{2}+\mathrm{D}_{\mathrm{a}}^{2}+\mathrm{D}_{\mathrm{b}}^{2}+\mathrm{D}
$$

From ( 55 ) it can be seen that $\dot{\mathrm{L}}<0$ as long as:

$$
\|\mathrm{r}\|>\frac{\Delta}{\mathrm{K}_{\mathrm{v} \min }},\|\tilde{\mathrm{W}}\|>\frac{\mathrm{D}_{\mathrm{w}}}{\mathrm{k}_{\mathrm{w}}}+\sqrt{\frac{\Delta}{\mathrm{k}_{\mathrm{w}}}},\|\tilde{\mathrm{a}}\|>\frac{\mathrm{D}_{\mathrm{a}}}{\mathrm{k}_{\mathrm{a}}}+\sqrt{\frac{\Delta}{\mathrm{k}_{\mathrm{a}}}},\|\tilde{\mathrm{b}}\|>\frac{\mathrm{D}_{\mathrm{b}}}{\mathrm{k}_{\mathrm{b}}}+\sqrt{\frac{\Delta}{\mathrm{k}_{\mathrm{b}}}} .
$$


International Journal of Artificial Intelligence \& Applications (IJAIA), Vol.2, No.2, April 2011

According to a standard Lyapunov theorem extension, that proves that $r, \tilde{W}, \tilde{a}$ and $\tilde{b}$ are UUB. Since $\mathrm{W}, \mathrm{a}$ and $\mathrm{b}$ are bounded, $\hat{\mathrm{W}}$, $\hat{\mathrm{a}}$ and $\hat{b}$ are also bounded. This fact concludes the stability proof.

\section{REFERENCES}

[1] L.-X. Wang, Adaptive Fuzzy Systems and Control: Design and Stability Analysis. Englewood Cliffs, NJ: Prentice Hall, 1994.

[2] S. Commuri and F. L. Lewis, "CMAC Neural Networks for Control of Nonlinear Dynamical Systems: Structure, Stability and Passivity" Automatica, Volume 33, Issue 4, April 1997, pp 635-641

[3] S.-D, Wang., Lin C.-K., "Adaptive tuning of the fuzzy controller for robots", Fuzzy Sets and Systems, Volume 110, Issue 3, pp. 351-363, 2000

[4] J.H.Kim, F. L. Lewis, "High-level feedback control with neural networks", World Scientific, Singapoore, 1998

[5] F. L. Lewis, K. Liu, R. R. Selmic, and Li-Xin Wang, "Adaptive fuzzy logic compensation of actuator deadzones," J. Robot. Sys., vol. 14, no. 6, pp. 501-511, 1997.

[6] G. Feng, "An Approcah to Adaptive Control of Fuzzy Dynamic Systems", IEEE Trans. On Fuzzy Systems, Vol. 10, No. 2, pp. 268-275, 2002

[7] Y-G. Piao, H.-G. Zhang, "Design of fuzzy direct adaptive controller and stability analysis for a class of nonlinear system", Proceedings of the 1998 American Control Conference, Vol. 4, pp. 2274-2275, 1998

[8] N. Golea, A. Golea, "Design of fuzzy direct adaptive controller and stability analysis for a class of nonlinear system", Proceedings of the 2002 IEEE International Conference on Fuzzy Systems FUZZ-IEEE'02", Vol. 1, pp. 330-334, 2002

[9] H. Ying, G. Chen, "Stability analysis of nonlinear fuzzy PI control systems", Third International Conference on Industrial Fuzzy Control and Intelligent Systems IFIS '93, pp. 128-133, 1993

[10] H.X. Li, Z.H. Miao, E.S. Lee, "Variable universe stable adaptive fuzzy control of a nonlinear system", Computers \& Mathematics with Applications, Volume 44, Issues 5-6, pp. 799-815, September 2002

[11] L.-X. Wang, "Stable adaptive fuzzy controllers with application to inverted tracking", IEEE Trans. Syst., Man, Cybernet.-Part B 26 (5) (1996) 677-691. 41

[12] K.M., Eksioglu, G. Lachiver, G. "A cognitive model for context dependent fuzzy knowledge", 18th International Conference of the North American Fuzzy Information Processing Society, 1999. NAFIPS, pp. 443-447, 1999

[13] L.-X. Wang and J. M. Mendel, "Fuzzy basis functions, universal approximation, and orthogonal least-square learning," IEEE Trans. Neural Networks, vol. 3, no. 6, pp. 807-814, 1992.

[14] F. L. Lewis, K. Liu, and A. Yesilidrek, "Neural net robot controller with guaranteed tracking performance," IEEE Trans. Neural Networks, vol. 6, no. 3, pp. 703-715, 1995.

[15] A.A. Berryman., Population Systems: A General Introduction, Plenum Press, New York \& London, 1981

[16] F.L. Lewis, S. Jagannathan, and A. Yesildirek, Neural Network Control of Robot Manipulators and Nonlinear Systems, Taylor and Francis, London, 1998.

[17] K.J Astrom, Wittenmark, B., Adaptive control, 2nd edition, Addison-Wesley Publishing Company, 1995

[18] A.G. Barto, "Reinforcement learning and adaptive critic methods," Handbook of Intelligent Control, pp. 469-492, Van Nostrand Reinhold, New York, 1992. 
International Journal of Artificial Intelligence \& Applications (IJAIA), Vol.2, No.2, April 2011

[19] J. Campos and F.L. Lewis, "Adaptive critic neural network for feedforward compensation," Proc. American Control Conf., vol. 4, pp. 2813 -2818, San Diego, 1999

[20] D. V. Prokhorov, D. C. Wunsch, "Adaptive Critic Designs", IEEE Transactions on Neural Netwroks, Vol. 8, No. 5, September 1997

[21] P. J. Werbos, "Neurocontrol and elastic fuzzy logic: Capabilities, Concepts and Applications", IEEE Trans. On Industrial Electronics, Vol. 40, No. 2, pp. 170-180, 1993

\section{Authors}

Ognjen Kuljaca received his B.Sc and M.Sc. degrees from Faculty of Electrical Engineering and Computing in Zagreb, University of Zagreb in 1994 and 1998, respectively. Between 1994 and 1999 he was with Control Systems Department, Brodarski Institute, Zagreb, Croatia. He finished his Ph.D. study in Electrical Engineering at The University of Texas in Arlington in 2003. In 2004 he joined Alcorn State University, Mississippi, USA where he served as Assistant Professor at Department of Advanced Technologies and Associate Director of Sensors and

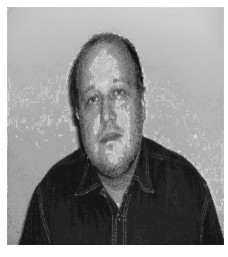
Automation Laboratory at Systems Research Institute. From 2010 he is again with Brodarski Institute, Zagreb, Croatia as lead researcher. His research and professional interests are in optimal control, neural networks and fuzzy control, power systems control and industrial automation.

Jyotirmay Gadewadikar received his Bachelor's degree in Electronics and Instrumentation Engineering from SGS Inst. of Tech. and Science, Indore, India in 1997. He has worked for Tata Steel as a Senior Officer and was involved with installation and commissioning in the Cold Rolling Mill Project. He received the Master's of Science in Electrical Engineering in 2003, and Ph. D. in 2007. In 2007 he joined Alcorn State University, Mississippi, USA where he serves as Assistant Professor at Department of Advanced Technologies and Director of Sensors and

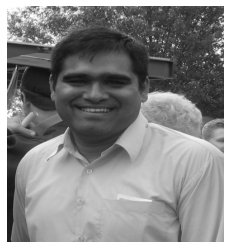
Automation Laboratory at Systems Research Institute. His research interests include $\mathrm{H} \infty$ control, output feedback control, helicopter UAV control, electromechanical systems, and Automated Testing and Measurement tools.

F.L. Lewis, Fellow IEEE, Fellow IFAC, Fellow U.K. Institute of Measurement \& Control, PE Texas, U.K. Chartered Engineer, is Distinguished Scholar Professor and Moncrief-O'Donnell Chair at University of Texas at Arlington's Automation \& Robotics Research Institute. He obtained the Bachelor's Degree in Physics/EE and the MSEE at Rice University, the MS in Aeronautical Engineering from Univ. W. Florida, and the Ph.D. at Ga. Tech. He works in feedback control, intelligent systems, distributed control systems, and sensor networks. He is author of 6 U.S. patents, 216

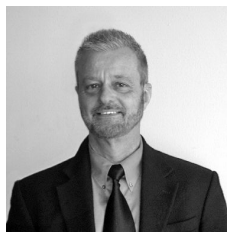
journal papers, 330 conference papers, 14 books, 44 chapters, and 11 journal special issues. He received the Fulbright Research Award, NSF Research Initiation Grant, ASEE Terman Award, Int. Neural Network Soc. Gabor Award 2009, U.K. Inst Measurement \& Control Honeywell Field Engineering Medal 2009. Received Outstanding Service Award from Dallas IEEE Section, selected as Engineer of the year by Ft. Worth IEEE Section. Listed in Ft. Worth Business Press Top 200 Leaders in Manufacturing. He served on the NAE Committee on Space Station in 1995. He is an elected Guest Consulting Professor at South China University of Technology and Shanghai Jiao Tong University. Founding Member of the Board of Governors of the Mediterranean Control Association.

Jyotirmay Gadewadikar received his Bachelor's degree in Electrical Engineering from University of Maribor, Slovenia in 1996. He received the Master's of Science in Electrical Engineering in 2000, and Ph. D. in 2006., both from University of Zagreb, Croatia. In 1996 he joined Brodarski Institute, Zagreb, Croatia, where he serves as Lead Researcher at Control Systems Department. His research interests include fault tolerant control, water turbines control, electromechanical systems, and automated testing and measurement tools

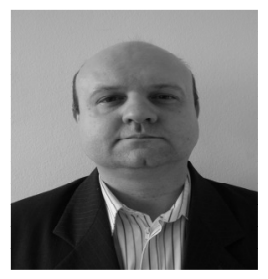

